\title{
Ground-penetrating radar study of the Cena Bog, Latvia: linkage of reflections with peat moisture content
}

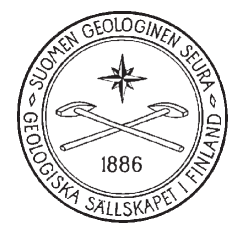

\author{
JĀNIS Karušs*and DĀVIDS BĒRZIN̦Š \\ University of Latvia, Faculty of Geography and Earth Sciences, Alberta Street 10, \\ LV 1586, Riga, Latvia
}

\begin{abstract}
Present work illustrates results of the ground-penetrating radar (GPR) study of the Cena Bog, Latvia. Six sub-horizontal reflections that most probably correspond to boundaries between sediments with different electromagnetic properties were identified. One of the reflections corresponds to bog peat mineral bottom interface but the rest are linked to boundaries within the peat body. The radar profiles are incorporated with sediment cores and studies of peat moisture and ash content, and degree of decomposition. Most of the electromagnetic wave reflections are related to changes in peat moisture content. The obtained data show that peat moisture content changes of at least $3 \%$ are required to cause GPR signal reflection. However, there exist reflections that do not correlate with peat moisture content. As a result, authors disagree with a dominant opinion that all reflections in bogs are solely due to changes in volumetric peat moisture content.
\end{abstract}

Keywords (GeoRef Thesaurus, AGI): geophysics, electromagnetic methods, peat, ground penetrating radar, moisture, Latvia.

*Corresponding author (e-mail: janis.karuss@inbox.lv)

Editorial handling: Atko Heinsalu (heinsalu@gi.ee)

\section{Introduction}

Ground-penetrating radar (GPR) is a widely used tool for shallow subsurface exploration. It is used in geological (Pueyo-Anchuela et al., 2009; Girardi \& Davis, 2010), archaeological (Porsani et al., 2010; Damiata et al., 2013) and civil engineering studies (de Castro \& Branco, 2003; Orlando \& Slob, 2009). During radiolocation profiling a short electromagnetic impulse, usually one-and-a half periods long, is generated in the transmitter antenna. This impulse travels through the ground and is partially reflected from the boundaries of sediment layers with different electromagnetic properties. These reflections are detected by a receiving antenna.

GPR has been extensively used in wetland research for more that a two decades (Halleux, 1990; Holden et al., 2002; Musgrave \& Binley, 2011). In 
early applications of GPR to study peat deposits, it was recognized that it is relatively easy to identify a reflection related to mineral bottom of the bog (Halleux, 1990; Hanninen, 1992). Also it is frequently used for peat thickness measurements (Lowry et al., 2009; Comas et al., 2011; van Bellen et al., 2011). Some authors have also used GPR for characterization of the sediments that forms mineral bottom of bog (Comas et al., 2005a; Musgrave \& Binley, 2011).

From the first attempts at GPR profiling in bogs (Hanninen, 1992; Sass et al., 2010) it was seen that the obtained radar images also display reflections relating to boundaries between peat layers. In numerous studies, researchers have tried, with varying success, to link the obtained reflections with changes in specific properties of peat.

It is generally accepted that reflections are related to peat moisture content changes (Holden et al., 2002; Slater and Reeve, 2002; Comas et al., 2004; Kettridge et al., 2008; Plado et al., 2011; de Oliveira et al., 2012). Further, several authors (Slater \& Reeve, 2002; Kettridge et al., 2008; Comas et al., 2011) argue that changes in peat moisture content are related to other properties of peat, such as ash content, density, botanical composition and degree of decomposition. Thereby, GPR can potentially be used for identification peat boundaries of various properties, e.g., to correlate GPR signal reflections with boundaries of peat layers characterised by different degree of decomposition (Kettridge et al., 2008; Plado et al., 2011) or different botanical composition (Hanninen, 1992; Sass et al., 2010). These results are, however, not unambiguous as there is still no widely-accepted opinion about the effect of various peat properties on the propagation and reflection of the GPR signal.

The generally-accepted opinion that moisture content change is the major factor that influences electromagnetic wave propagation speed $\left(V_{E M W}\right)$ in peat is most likely correct. First, dielectric permittivity of water is high, 81 according to Buchner et al. (1999), and even small variations in the peat volumetric water content modify the dielectric permittivity of sediments. Second, some authors have proven that even minor changes in volumetric water content in peat influence $v_{E M W}$ (Comas \& Slater, 2007; Parsekian et al., 2012).

It is ambiguous, however, to directly use the results of the previously mentioned research methods in the field. However, various aspects (such as attenuation, geometric spreading, scattering) must be taken into account. As a result, it is not possible to estimate the change in peat moisture content required in order to cause a detectable GPR signal reflection.

The goal of present study is to estimate the magnitude of differences in moisture content of peat layers required to cause reflection at their boundary. Additionally, influence of the degree of peat decomposition and peat ash content on propagation and reflection of the GPR signal are evaluated.

\section{Field site}

Cena Bog (centred at 56 51'26.5” N; 2351'3.4” E; Fig. 1) with an area of $\sim 90 \mathrm{~km}^{2}$, located $\sim 12 \mathrm{~km}$ SW of Riga (Latvia) has served as study site. The average peat thickness of the bog is $\sim 2 \mathrm{~m}$ and maximum $6 \mathrm{~m}$ respectively (Kalnina, 2008). Opened bog pools (Fig. 1c) are common in central part of the bog, where the thickness of the peat body is the greatest. The area of most pools is less than $0.02 \mathrm{~km}^{2}$, although the biggest one, Lake Skaista, covers $0.183 \mathrm{~km}^{2}$.

Sphagnum dominated peat occurs in the central part of bog, although Phragmites peat has been recognized in the peripheral part of the bog (Kalnina, 2008). The degree of decomposition of peat using percentage evaluation varies in between 15-20\% (Klavins et al., 2008). The underlying mineral basement of the bog consists of the Baltic Ice Lake sands and clayey sands. Cena Bog may have started to form 5000-6000 years ago due to lack of water drainage from the local depression (Kalnina, 2008).

\section{Methods}

The field data were collected in April 2014. In the course of the study we installed two GPR profiles (Fig. 1d), Profile A (onset - 56 51'23.7”N; 2349' 37.2”E, end - 56 $51^{\prime} 25.09^{\prime \prime} \mathrm{N}$; 2349'38.13”E, 
a)

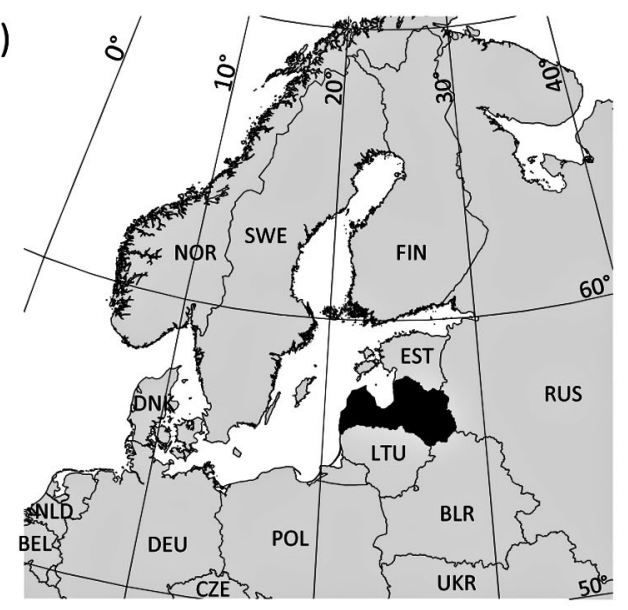

d)

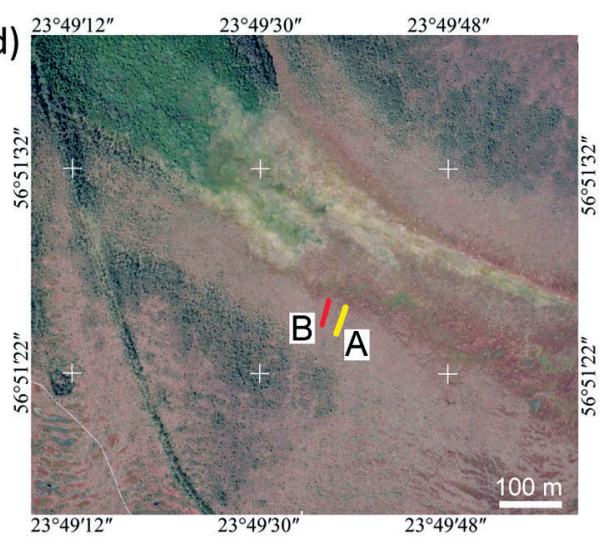

b)

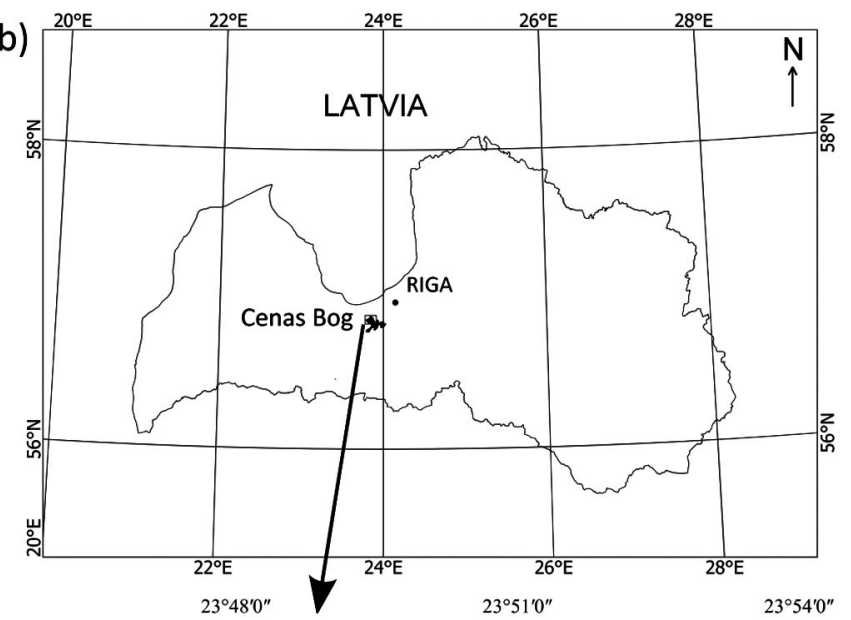

c)

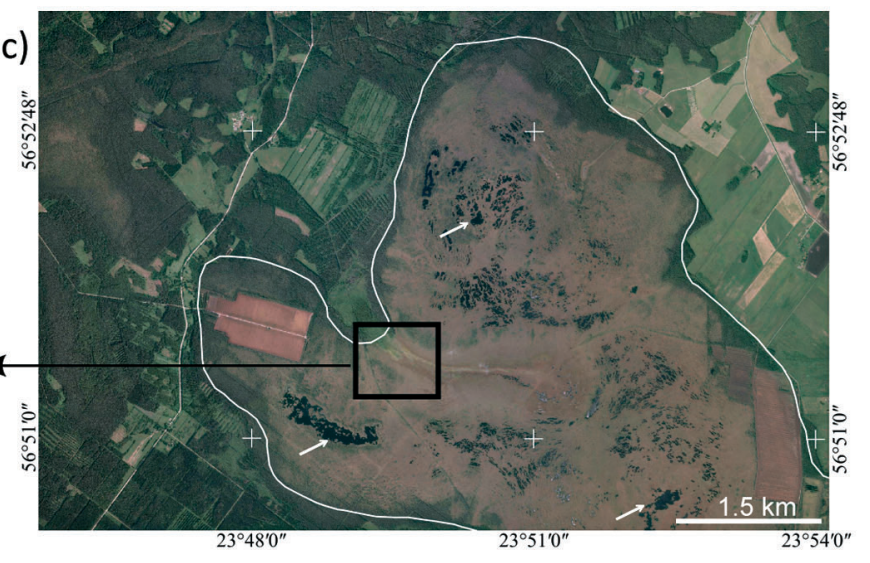

Fig. 1. a) Map of northern Europe, Latvia is marked with black colour. b) Map of Latvia. c) Northern part of Cena Bog, white line outlines the bog and with white arrows biggest bog pools are indicated. d) Yellow line marks GPR Profile A and red line marks GPR Profile B.

length $41 \mathrm{~m}$ ) and Profile B (onset - 56 $51^{\circ} 24.2^{\prime \prime} \mathrm{N}$; $23^{\circ} 49^{\prime} 35.9^{\prime \prime} \mathrm{E}$, end $-56^{\circ} 51^{\prime} 25.5^{\prime \prime} \mathrm{N}$; $23^{\circ} 49^{\prime} 36.6^{\prime \prime} \mathrm{E}$, length of the profile is $38 \mathrm{~m}$ ). The Profile A was used to determine the relationship between the GPR signal reflections and changes in general peat properties, such as moisture content, ash content and degree of decomposition. While taking into account the data obtained from GPR Profile A, it was decided to install a second GPR profile in close proximity to GPR Profile A solely in order to determine the relationship between the GPR signal reflections and moisture content changes in the peat section.

A peat section of the bog was measured manually by coring (corer with $50-\mathrm{cm}$-long sample chamber) and peat coring took place in eleven locations. Along GPR Profile A three cores were drilled, while along GPR profile B eight cores were taken. Cores were transported to the laboratory in faculty of Geography and Earth Sciences, University of Latvia where peat moisture and ash content were analysed at 5-cm-intervals. Peat decomposition degree was analysed in Ltd "Environmental consultation bureau" laboratory at 20-cm-intervals.

Peat moisture content was determined by weighting the samples before and after drying them at $105^{\circ} \mathrm{C}$ for 24 hours. During sampling it was apparent that up to a depth of $\sim 1 \mathrm{~m}$ the peat subsamples were rapidly losing water. Thus we consider that the results of moisture content analysis are 
reliable for samples obtained from a depth of at least $1 \mathrm{~m}$.

Further, ash content was determined by the loss on ignition method, by burning the samples at 800 ${ }^{\circ} \mathrm{C}$ for 2 hours. Degree of decomposition of peat was described by using a light microscope (Malterer et al., 1992).

Accuracies of peat moisture content and ash content analysis were determined by using method of fractional uncertainties (Taylor, 1996). Calculated moisture content and ash content errors varied accordingly from 0.005 to $0.089 \mathrm{wt} \%$ and from 0.047 to $0.74 \mathrm{wt} \%$ for obtained samples. For few peat sub-surface samples calculated ash content error was $\sim 1.5 \mathrm{wt} \%$.

For optimum GPR data quality in peatlands, Sass et al. (2010) recommend using an antenna system with a central frequency close to $250 \mathrm{MHz}$. Following Zond 12-e GPR was applied by using a common offset configuration with a $300 \mathrm{MHz}$ antenna system. It was determined that central frequency for reflections that were identified in obtained radar images is $\sim 120 \mathrm{MHz}$ that corresponds to wavelength of $\sim 30 \mathrm{~cm}$ (assuming that value of dielectric permittivity is 73). Data were recorded using a 500 ns time window. Profile length was measured with a measuring tape. During recording of common offset profile, time triggering mode of sounding was used and 80 traces per second were recorded.

To determine $V_{E M W}$ a common midpoint method (CMP) according to Neal (2004) was applied using $300 \mathrm{MHz}$ antenna as transmitter and $500 \mathrm{MHz}$ antenna as receiver. It was necessary to use $500 \mathrm{MHz}$ antenna as receiver because construction of $300 \mathrm{MHz}$ antenna system prohibits separation of its transmitter and receiver antennas. Both antennas were moved apart in respect to a central fixed position in a direction parallel to common offset profile. The distance between separate traces was set to $10 \mathrm{~cm}$, and the final distance between transmitting and receiving antennas was $\sim 10 \mathrm{~m}$. One CMP measurement was performed on both GPR profiles. The exact positions for the CMP measurements were chosen using common offset radar images in positions where all identifiable sub- horizontal reflections were distinct and clearly traceable.

The raw GPR data were processed and analysed by Prism 2.5 software. To compensate for signal losses and improve the informative reflections: (i) time-dependent signal gain function; (ii) Ormsby band-pass filter with low frequency cut off at 35 $\mathrm{MHz}$ and high frequency cut off at $245 \mathrm{MHz}$; (iii) background removal filter and (iv) normal moveout correction (Neal, 2004; Karušs, 2014) were used.

After processing of recorded radar images, depths from which the GPR signal reflections were received at each core were determined. For that, first, the time after which the reflections were received using common offset GPR profiles at each core was determined.

Second, using CMP data the average $V_{E M W}$ up to the reflection of interest was calculated by applying linear regression of the squared two-way travel time versus the squared transmitterreceiver separation (Neal, 2004).

Not all the reflections identified in the common offset GPR profiles show up in the CMP radar images. Depth of such reflections was calculated by using $V_{E M W}$ determined using next deepest reflection traceable in the CMP radar image.

Calculated $V_{E M W}$ values and travel time were used to calculate the depth from which each reflection was received at each coring locality. It was assumed that the calculated depths of the reflector surfaces differ from the actual depths of the reflector surfaces with similar error as calculated depth of bog mineral bottom for a particular core differs from actual measurement in that coring. As biggest difference between those values was $6 \mathrm{~cm}$, it was assumed that depth of each reflector is determined with precision of $+1-6 \mathrm{~cm}$.

Using Complex Refractive Index Model (CRIM; Parsekian et al., 2012) bulk dielectric permittivity $\left(\varepsilon_{b}\right)$ for each 5-cm-interval sample was calculated:

$$
\varepsilon_{b}^{a}=\theta \varepsilon_{w}^{a}+(1-\phi) \varepsilon_{s}^{a}+(\phi-\theta) \varepsilon_{g}^{a},
$$

where $\theta$ - volumetric water content; $\varphi$ - porosity; $\varepsilon_{s}$ - dielectric permittivity of the solid phase (set to 
2; Comas et al., 2005b); $\varepsilon_{w}$ - dielectric permittivity of water; $\varepsilon_{g}$ - dielectric permittivity of air. In the course of calculations $\alpha$ was set to 0.35 as commonly used for peat (Strack \& Mierau, 2010), $\varepsilon_{w}$ was set to 83.83 (selected for in the field measured average temperature of peat $10^{\circ} \mathrm{C}$ ) and it was assumed that gas content is negligible $(\varphi=\theta)$. For peat particles density values reported by Redding \& Devito (2006) were used.

Using with CRIM calculated values of $\varepsilon_{b}$ and from obtained radar images determined two-way travel times, depths from which the reflections have been received were calculated. Depth values of reflectors, calculated with CRIM, were compared to those values obtained with $V_{E M W}$ that were determined with CMP. As a result it was possible to evaluate effect of water content alone to $\varepsilon_{b}$.

\section{Results}

Along a GPR Profile A (Fig. 2a), a mineral bottom composed of sand at a depth of $\sim 4.5 \mathrm{~m}$ is overlain

\section{a)}

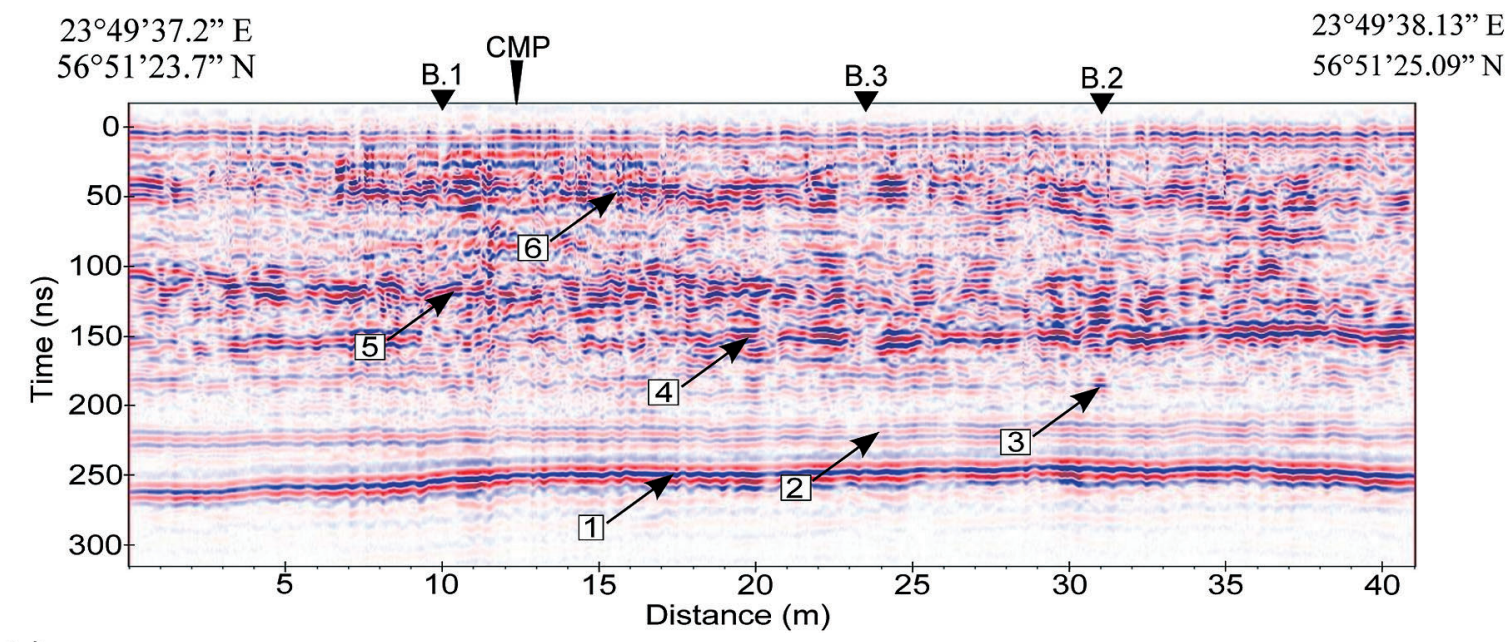

b)

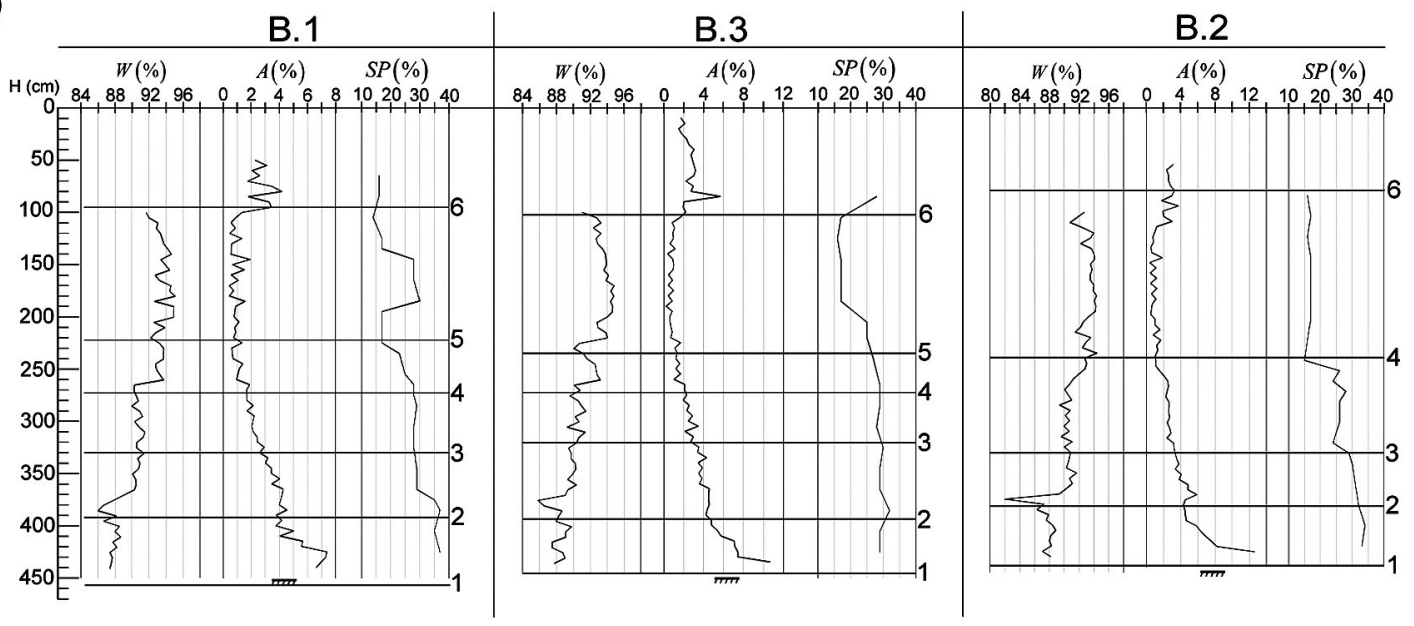

Fig. 2. a) GPR survey image along the Profile A (see Fig. 1 for location). B.1 to B.3 indicate core positions; CMP locates a common midpoint study (see Fig. 3a). Number 1 is the mineral-peat contact reflection, number 2-6 are reflections within the peat. b) Down-core variations of peat moisture content (W), ash content (A), and degree of decomposition (SP). Numbers at the right side and horizontal lines correspond to position of reflections acquired from common offset profiles while black thick lines corresponds to bog mineral bottom. 
by a layer $1.6 \mathrm{~m}$ deep of fen-type peat. The upper part of the fen-type peat mainly consists of Carex remains, whereas the basal part consists of wood and sedge remnants. The characteristic degree of decomposition for this layer is $\sim 30 \%$, while the moisture content varies between 83.0-91.5\%, and ash content gradually increases from $2 \%$ at the top to $10 \%$ at the base of the layer.

Fen-type peat is overlain by a layer of $\sim 0.2 \mathrm{~m}$ of transitional peat. Various grasses, sedges and Hypnum moss are the peat's main components. The characteristic degree of decomposition for this layer is $26 \%$, while the moisture content varies from 90 to $93 \%$ and the ash content is $\sim 2 \%$.

The upper part of the sediment consists of a layer of $\sim 2.6 \mathrm{~m}$ of raised bog-type peat that consists of S. fuscum, S. magellanicum, and S. angustifolium moss and cotton grass remnants. The characteristic degree of decomposition for this layer is $18 \%$, while the moisture content varies between $91-95 \%$ and the ash content is $\sim 1.4 \%$ (Fig. $2 \mathrm{~b}$ ).

In Profile A, six sub-horizontal GPR reflections occur (named 1 to 6 from the deepest to the shallowest; Fig. 2a), which are related to the boundaries between layers with different electromagnetic properties. These reflections are generally sub-horizontal and are more or less traceable, although in some parts of the radar image they have low amplitude. Instead, it is possible to identify zones of reflections that are related to the boundaries for peat layers. This observation suggests that the boundaries between peat layers with different electromagnetic properties are not continuously distinct.

The common mid-point study (Fig. 3a) on Profile A traces three reflections (1, 2, and 5) (Table 1).

The depth from which Reflection 1 was received differs from the depth at which the bog's mineral bottom was reached in the boreholes by no more than $5 \mathrm{~cm}$ (Fig. 2b). Accordingly, we related Reflection 1 to the bog's mineral bottom.

Identified in all three cores, at a depth of approximately $3.8 \mathrm{~m}$, there exists a peat interval with a relatively low moisture content (4\% lower than surroundings). Reflection 2 was received from each coring point directly below this interval. Consequently, Reflection 2 was considered to relate to a distinct moisture content change.

At coring points B.1 and B.3, GPR Reflection 4 was received from a depth of approximately 2.7 $\mathrm{m}$, whereas at a core depth of $2.6 \mathrm{~m}$ there was a distinct 3-4\% decrease in the peat moisture content (Fig. 2b). In core B.2, peat moisture content change is more gradual; however, they are coincident with GPR-derived Reflection 4. Accordingly, Reflection 4 is also related to peat moisture content changes.

It is difficult to relate Reflections 3, 5, and 6 to any of the changes in peat section parameters. For

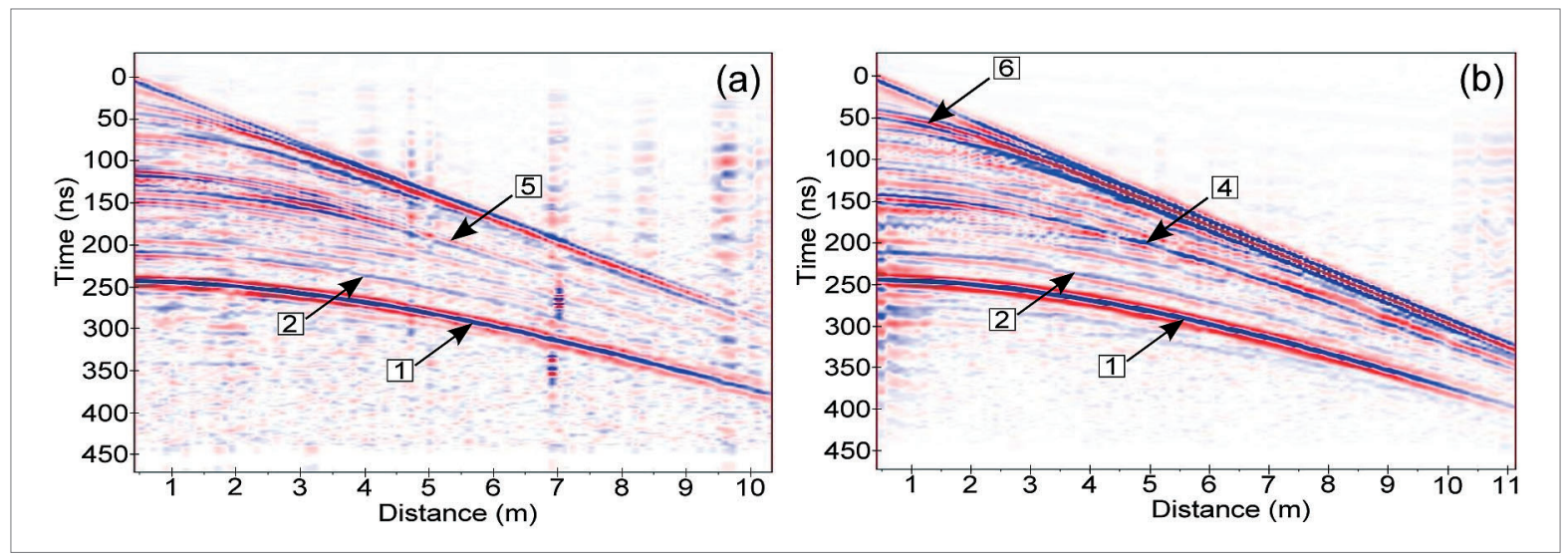

Fig. 3. a) Results of common mid-point measurements on GPR Profile A (see Figs. 1 and 2a for location). The numbered reflections refer to reflections from mineral base (1) and within the peat body (2 and 5). b) Results of common mid-point measurements on ground-penetrating radar Profile B (see Figs. 1 and $4 a$ for location). The numbered reflections refer to reflections from mineral base (1) and within the peat body $(2,4,6)$. 
Table 1. Results of calculations associated with 6 identified radar reflections.

\begin{tabular}{|c|c|c|c|c|c|c|c|}
\hline $\begin{array}{l}. \frac{0}{0} \\
\frac{0}{0} \\
\frac{0}{4} \\
\frac{0}{\alpha}\end{array}$ & 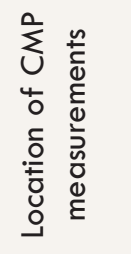 & $\begin{array}{l}\bar{E} \\
\underline{E} \\
5 \\
\vdots\end{array}$ & 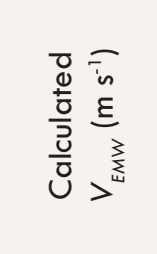 & 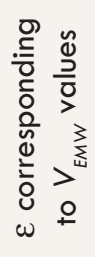 & 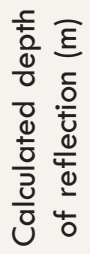 & 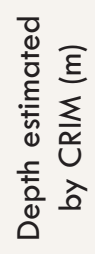 & 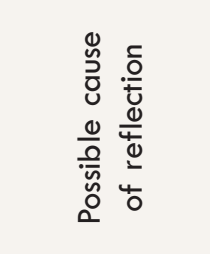 \\
\hline \multirow{2}{*}{1} & Profile A & 255 & 35061375 & 73.1 & 4.47 & 4.42 & \multirow{2}{*}{ Mineral bottom } \\
\hline & Profile B & 248 & 35162480 & 72.7 & 4.36 & 4.32 & \\
\hline \multirow{2}{*}{2} & Profile A & 225 & 34205263 & 76.8 & 3.85 & 3.87 & \multirow{2}{*}{$\begin{array}{c}\text { Moisture } \\
\text { content changes }\end{array}$} \\
\hline & Profile B & 222 & 34510868 & 75.5 & 3.83 & 3.90 & \\
\hline 4 & $\begin{array}{l}\text { Profile A } \\
\text { Profile B }\end{array}$ & $\begin{array}{l}\text { n.a. } \\
153\end{array}$ & $\begin{array}{c}\text { n.a. } \\
33719431\end{array}$ & $\begin{array}{l}\text { n.a. } \\
79.0\end{array}$ & $\begin{array}{l}\text { n.a. } \\
2.60\end{array}$ & $\begin{array}{l}\text { n.a. } \\
2.62\end{array}$ & $\begin{array}{c}\text { Moisture } \\
\text { content changes }\end{array}$ \\
\hline \multirow{2}{*}{5} & Profile A & 125 & 34102786 & 77.3 & 2.13 & 2.25 & \multirow{2}{*}{$?$} \\
\hline & Profile B & n.a. & n.a. & n.a. & n.a. & n.a. & \\
\hline \multirow{2}{*}{6} & Profile A & n.a. & n.a. & n.a. & n.a. & n.a. & \multirow{2}{*}{$\begin{array}{c}\text { Moisture } \\
\text { content changes }\end{array}$} \\
\hline & Profile B & 56.4 & 33941126 & 78.0 & 0.99 & 0.95 & \\
\hline
\end{tabular}

CMP = common midpoint method; TWTT = two-way travel time; $V_{E M W}=$ speed of the electromagnetic wave; $\varepsilon=$ relative dielectric permittivity; CRIM = Complex Refractive Index Model.

example, in core B.3 the depth from which Reflection 5 was received coincides with rather distinct peat moisture content decrease, whereas in core B.1 similar peat moisture content changes are not evident (Fig. 2b).

In general, the reflections that were identified on GPR Profile B have the same characteristics as those that were seen on GPR Profile A (Fig. 4a). Moreover, the reflections on Profile $\mathrm{B}$ are more pronounced. The same applies to CMP results (Fig. 3b).

Also in Profile B, the depth of the interface between the peat and the underlying mineral sediments that were calculated from GPR data (Reflection 1) correlates well with the manual coring measurements (Fig. 4b). Reflections 2 and 6 correlate well with detected changes in peat moisture content.
In each of the eight cores moisture content changes coincide with the calculated depth of GPR Reflection 4 (Fig. 4b). The GPR-derived Reflection 4 (at coring points B.2 and B.4-B.11) correlates with a peat moisture content decrease as well as with a boundary between light-coloured raised bog-type peat with a relatively low degree of decomposition and dark-coloured transitional and fen-type peat with a relatively high degree of decomposition (Fig. 5).

As a contrary picture, the relationship between GPR Reflection 4 with a peat-level of decomposition that was observed in cores B. 1 and B.3 is limited. In core B. 1 the boundary between light-coloured raised bog-type peat and dark-coloured transitional or fen-type peat is more gradual, while in core B.3 some minor fluctuations in the degree of peat decomposition occur (Fig. 5a). 


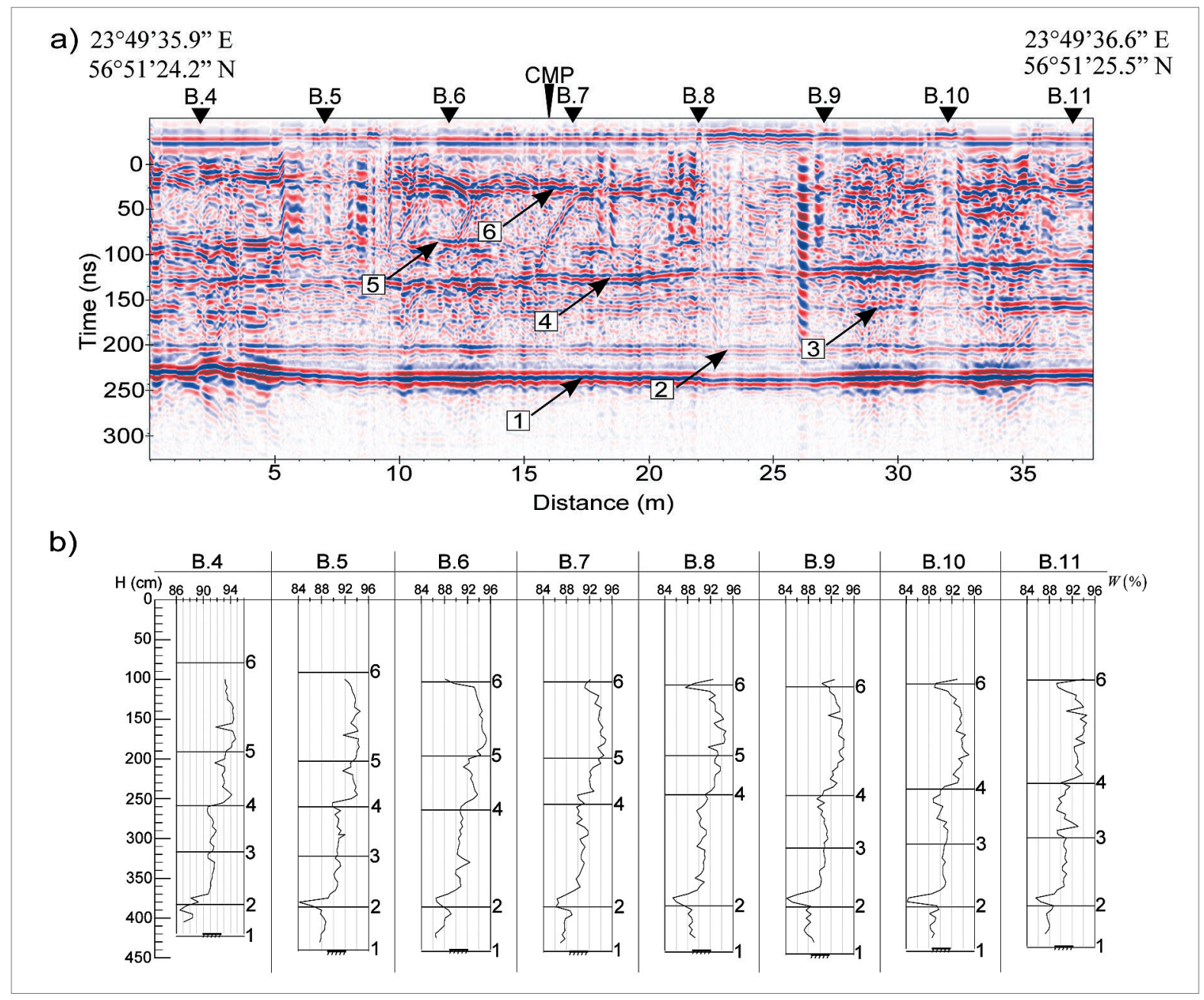

Fig. 4. a) Radar image along the Profile B (see Fig. 1 for location). B.4 to B.11 indicates locations of cores; CMP locates a common midpoint study (see Fig. 3b). Numbers (1 to 6; see text for descriptions) refer to reflections from mineral base (1) and within the peat body (2 to 6). b) Moisture content of peat along cores B.4 to B.11. Numbers at the right side and horizontal lines correspond to position of reflections acquired from common offset profiles while black rectangles corresponds to bog mineral bottom.

As in GPR Profile A, in Profile B GPR Reflection 3 is only partially related to peat moisture content changes. Reflection 5, imaged by GPR, does not accord with any peat properties.

\section{Discussion}

Present data show that a moisture content change of at least $3 \%$ is required in order to result in a detectable clear GPR signal reflection. These results are consistent with the results that were reported by Parsekian et al. (2012). They demonstrated that increase in the peat moisture content of $\sim 3 \%$ would result in increase of dielectric permittivity of $\sim 8 \%$ and would substantially change the GPR signal propagation speed. At the laboratory level Parsekian et al. (2012) were able to detect moisture changes of $1 \%$ using GPR. Such small differences were however not detectable in present field study, probably due to high signal attenuation.

In the study it was possible to relate most of the reflections in terms of changes in peat moisture content. The CRIM calculated values of $v_{E M W}$ also corresponded well with CMP calculated values of 


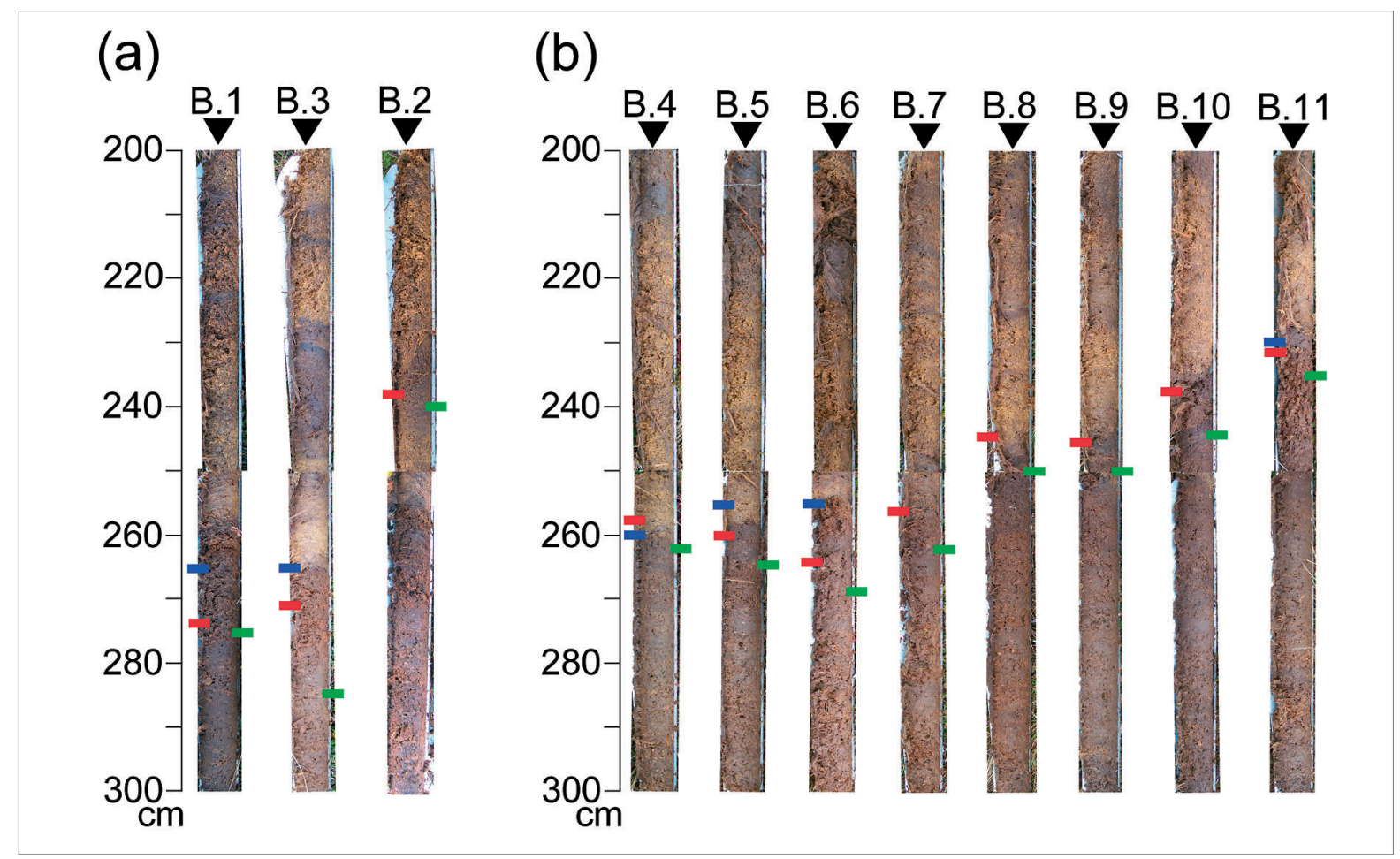

Fig. 5. a) Photographs of the peat cores obtained along GPR Profile A. b) Photographs of the peat cores obtained along GPR Profile B. Red rectangles mark the depth from which reflection 4 was received, green rectangles mark the depth from which reflection 4 was received as calculated by using CRIM and the blue rectangles mark the depth at which abrupt peat moisture content changes were identified. Light-coloured peat is raised bog type peat with degree of decomposition less than $20 \%$ while dark-coloured peat is transitional and fen type peat with degree of decomposition almost $30 \%$.

$v_{E M W}$ indicating the dominant role of water content in the values of $\varepsilon_{b}$ (Table 1; Fig. 5). In some cases, however, it was hard to separate the influence of moisture content changes to a particular reflection from the influence of peat decomposition changes (Fig. 2). In some cases, it was not at all possible to relate the reflections against volumetric moisture content changes (Fig. 4).

Results of this research disagree with the generally-accepted opinion that it is possible to explain all obtained reflections from bogs on the basis of volumetric moisture content changes only (Holden et al., 2002; Slater \& Reeve, 2002; Comas et al., 2004; Kettridge et al., 2008; Plado et al., 2011; de Oliveira et al., 2012). In the research calculated values of $v_{E M W}$ and the corresponding $\varepsilon \sim 73$ for a $92 \%$ moisture content (Table 1) are higher than the values that are reported in similar research $(\varepsilon$ $\sim 65$ for a $92 \%$ moisture content; Parsekian et al,
2012), although the volumetric moisture content in both cases is identical. If the volumetric moisture content is the only variable that influences the value of the light refractive index of peat, then values of $v_{E M W}$ must be equal.

As it was not possible to relate some of the obtained reflections directly with any of the determined properties of peat (moisture content, ash content, the degree of decomposition, botanical composition), other more complex mechanisms must be considered. For example, bound water has significantly different electromagnetic properties from free water (Kaatze, 2011). It is possible that the degree of decomposition and botanical composition of peat influences the amount of water molecules that are in a relatively bounded state. Following on from this, the bulk electromagnetic properties of peat that influences propagation and the reflection of a GPR signal are the function of 
the mutual interaction of peat moisture content, the degree of decomposition, and the botanical composition.

Generally it is assumed that it is possible to distinguish separate reflections from two boundaries if the distance between them is greater than one quarter of the wavelength of the transmitted signal (for present research $7 \mathrm{~cm}$ ) (Reynolds, 1997; Jol, 2009). The resolution of moisture content analysis was slightly higher, sitting at $5 \mathrm{~cm}$. So it is possible that there are some thin layers (thickness $\sim 2-3 \mathrm{~cm}$ ) with differing moisture content levels that were not detected by laboratory analysis. It should be noted that the vertical resolution of the GPR indicates the minimal distance that is required in order to distinguish between two separate reflections. In situations where the thickness of the layer is smaller than a quarter of the wavelength of the transmitted signal, it will be impossible to distinguish between two separate reflections from the layer boundaries. It will be, however, possible to detect one reflection in general from this thin layer.

Some authors (e.g. Jol, 2009) argue that changes in the physical properties of sediments must occur at an interval that is one quarter of the transmitted GPR signal wavelength in order to be detectable with GPR. The actual frequency of the used 300 $\mathrm{MHz}$ antenna was $\sim 120 \mathrm{MHz}$ with a corresponding wavelength of $30 \mathrm{~cm}(\varepsilon \sim 73)$. Consequently, any gradual changes in physical properties over an interval $>7 \mathrm{~cm}$ would not be detectable with the current antenna system. The present results demonstrate that gradual changes that happen over an interval $>10 \mathrm{~cm}$ produced a detectable reflection (Reflection 4 in cores B.6 and B.8, Fig. 4).

Due to the close relationship between water content, botanical composition, and the degree of decomposition of peat, it will be impossible to evaluate the influence of a particular peat property on the GPR signal reflection using only data that has been obtained in field experiments. Field data can provide valuable information about the cumulative effects of peat properties on GPR signal propagation and reflection, but it will still not be possible to distinguish which property's changes were crucial to a particular reflection. In future research it will be necessary to determine the dielectric permittivity of peat samples that exhibit various properties.

\section{Conclusions}

Water content has a significant effect on GPR signal propagation and reflection in peat. During the research it was estimated that $\sim 3 \%$ moisture content changes are required to trigger detectable GPR signal reflection. Nevertheless, it was not possible to relate all of the identified reflections to peat volumetric moisture content changes, and therefore other more complex mechanisms must be taken into account.

\section{Acknowledgements}

This work has been supported by the European Social Fund within the project "Support for Doctoral Studies at the University of Latvia". Helpful comments and suggestions from the editor Atko Heinsalu, and two anonymous reviewers are also acknowledged.

\section{References}

Buchner, R., Barthel, J. \& Stauber, J., 1999. The dielectric relaxation of water between $0{ }^{\circ} \mathrm{C}$ and $35^{\circ} \mathrm{C}$. Chemical Physics Letters 306, 57-63.

Comas, X., Slater, L. \& Reeve, A., 2004. Geophysical evidence for peat basin morphology and stratigraphic controls on vegetation observed in a Northern Peatland. Journal of Hydrology 295, 173-184. http://dx.doi.org/10.1016/ j.jhydrol.2004.03.008

Comas, X., Slater, L. \& Reeve, A., 2005a. Stratigraphic controls on pool formation in a domed bog inferred from ground penetrating radar (GPR). Journal of Hydrology 315, 4051. http://dx.doi.org/10.1016/j.jhydrol.2005.04.020

Comas, X., Slater, L. \& Reeve, A., 2005b. Spatial variability in biogenic gas accumulations in peat soils is revealed by ground penetrating radar (GPR). Geophysical Research Letters 32, L08401. http://dx.doi.org/10.1029/2004 GL022297

Comas, X. \& Slater, L., 2007. Evolution of biogenic gases in peat blocks inferred from noninvasive dielectric permittivity measurements. Water Resource Research 43, W05424. http://dx.doi.org/10.1029/2006WR005562

Comas, X., Slater, L. \& Reeve, A., 2011. Pool patterning in a northern peatland: Geophysical evidence for the role of postglacial landforms. Journal of Hydrology 399, 173- 
184. http://dx.doi.org/10.1016/j.jhydrol.2010.12.031

Damiata, B.N., Steinberg, J.M., Bolender, D.J. \& Zoëga, G., 2013. Imaging skeletal remains with ground-penetrating radar: comparative results over two graves from Viking Age and Medieval churchyards on the Stóra-Seyla farm, northern Iceland. Journal of Archaeological Science 40, 268-278. http://dx.doi.org/10.1016/j.jas.2012.06.031

de Castro, D.L. \& Branco, R.M.G.C., 2003. 4-D ground penetrating radar monitoring of a hydrocarbon leakage site in Fortaleza (Brazil) during its remediation process: a case history. Journal of Applied Geophysics 54, 127-144. http://dx.doi.org/10.1016/j.jappgeo.2003.08.021

de Oliveira, M.A.T., Porsani, J.L., de Lima, G.L., JeskePieruschka, V. \& Behling, H., 2012. Upper Pleistocene and Holocene peatland evolution in Southern Brazilian highlands as depicted by radar stratigraphy, sedimentology and palynology. Quaternary Research 77, 397-407. http:/ /dx.doi.org/10.1016/j.yqres.2011.12.006

Girardi, J.D. \& Davis, D.M., 2010. Parabolic dune reactivation and migration at Napeague, NY, USA: Insights from aerial and GPR imagery. Geomorphology 114, 530-541. http:/ /dx.doi.org/10.1016/j.geomorph.2009.08.011

Halleux, L., 1990. Ground penetrating radar applied to the study of peat bogs and moors. Annales de la Sociètè Gèologique de Belgique 113, 115-123.

Hanninen, P., 1992. Application of ground penetrating radar techniques to peatland investigations. Geological Survey of Finland Special Paper 16, 217-221.

Holden, J., Burt, T.P. \& Vilas, M., 2002. Application of groundpenetrating radar to the identification of subsurface piping in blanket peat. Earth Surface Processes and Landforms 27, 235-249. http://dx.doi.org/10.1002/esp.316

Jol, H. M., 2009. Ground Penetrating Radar: Theory and Applications. Elsevier Science, Oxford, 524 p.

Kaatze, U., 2011. Bound water: Evidence from and implications for the dielectric properties of aqueous solutions. Journal of Molecular Liquids 162, 105-112. http://dx.doi.org/ 10.1016/j.molliq.2011.06.012

Kalnina, L., 2008. Origin and development of Cena Mire. In: Pakalne, M. (Ed.), Mire Conservation and Management in Especially Protected Nature Areas in Latvia, 30-33.

Karušs, J., 2014. High precision calculation of move out correction in GPR measurements. European Scientific Journal, February 2014 Special Edition vol. 3, 206-210.

Kettridge, N., Comas, X., Baird, A., Slater, L., Strack, M., Thompson, D., Jol, H. \& Binley, A., 2008. Ecohydrologically important subsurface structures in peatlands revealed by ground-penetrating radar and complex conductivity surveys. Journal of Geophysical Research 113, G04030. http://dx.doi.org/10.1029/2008JG000787

Klavins, M., Sire, J., Purmalis, O. \& Melecis, V., 2008. Approaches to estimating humification indicators for peat. Mires Peat 3, 1-15.

Lowry, C.S., Fratta, D. \& Anderson, M.P., 2009. Ground penetrating radar and spring formation in a groundwater dominated peat wetland. Journal of Hydrology 373, 6879. http://dx.doi.org/10.1016/j.jhydrol.2009.04.023

Malterer, T.J., Verry, E.S. \& Erjavec, J., 1992. Fiber content and degree of decomposition in peats: review of national methods. Soil Science Society of America Journal 56, 1200-1211. http://dx.doi.org/10.2136/sssaj1992.0361 5995005600040033x

Musgrave, H. \& Binley, A., 2011. Revealing the temporal dynamics of subsurface temperature in a wetland using time-lapse geophysics. Journal of Hydrology 396, 258266. http://dx.doi.org/10.1016/j.jhydrol.2010.11.008

Neal, A., 2004. Ground-penetrating radar and its use in sedimentology: principles, problems and progress. EarthScience Reviews 66, 261-330. http://dx.doi.org/10.1016/ j.earscirev.2004.01.004

Orlando, L. \& Slob, E., 2009. Using multicomponent GPR to monitor cracks in a historical building. Journal of Applied Geophysics 67, 327-334. http://dx.doi.org/10.1016/ j.jappgeo.2008.09.003

Parsekian, A. D., Slater, L. \& Gimenez, D., 2012. Application of ground-penetrating radar to measure near-saturation soil water content in peat soils. Water Resources Research 48, W02533. http://dx.doi.org/10.1029/2011WR011303

Plado, J., Sibul, I., Mustasaar, M. \& Jōeleht, A., 2011. Groundpenetrating radar study of the Rahivere peat bog, eastern Estonia. Estonian Journal of Earth Sciences 60, 31-42. http://dx.doi.org/10.3176/earth.2011.1.03

Porsani, J.L., Jangelme, G.M. \& Kipnis, R., 2010. GPR survey at Lapa do Santo archaeological site, Lagoa Santa karstic region, Minas Gerais state, Brazil. Journal of Archaeological Science 37, 1141-1148. http://dx.doi.org/10.1016/ j.jas.2009.12.028

Pueyo-Anchuela, Ó., Soriano, A.P.J.M.A. \& Casas-Sainz, A.M., 2009. Characterization of karst hazards from the perspective of the doline triangle using GPR - Examples from Central Ebro Basin (Spain). Engineering Geology 108, 225-236. http://dx.doi.org/10.1016/j.enggeo.2009. 06.022

Redding, T.E. \& Devito, K.J., 2006. Particle densities of wetland soils in northern Alberta, Canada. Canadian Journal of Soil Science 86, 57-60. http://dx.doi.org/10.4141/S05061

Reynolds, J., 1997. An Introduction to Applied and Environmental Geophysics. Wiley, New York, 806 p.

Sass, O., Friedmann, A., Haselwanter, G. \& Wetzel, K.-F., 2010. Investigating thickness and internal structure of alpine mires using conventional and geophysical techniques. Catena 80, 195-203. http://dx.doi.org/10.1016/j.catena. 2009.11.006

Slater, L.D. \& Reeve, A., 2002. Case history: investigating peatland stratigraphy and hydrogeology using integrated electrical geophysics. Geophysics 67, 365-378. http:// dx.doi.org/10.1190/1.1468597 
Strack, M. \& Mierau, T., 2010. Evaluating spatial variability of free-phase gas in peat using ground-penetrating radar and direct measurement. Journal of Geophysical Research 115, G02010. http://dx.doi.org/10.1029/2009JG001045 Taylor, J.R., 1996. An Introduction to Error Analysis: The Study of Uncertainties in Physical Measurements. University Science Books, California, 327 p. van Bellen, S., Dallaire, P.-L., Garneau, M. \& Bergeron, Y., 2011. Quantifying spatial and temporal Holocene carbon accumulation in ombrotrophic peatlands of the Eastmain region, Quebec, Canada. Global Biogeochemical Cycles 25, GB2016. http://dx.doi.org/10.1029/2010GB003877 